\begin{tabular}{|c|c|c|}
\hline 7 & $\begin{array}{c}\text { International Journal of Current Research } \\
\text { and Academic Review }\end{array}$ & a. \\
\hline $\begin{array}{l}\text { EXCELLENT } \\
\text { PUBLISHERS }\end{array}$ & 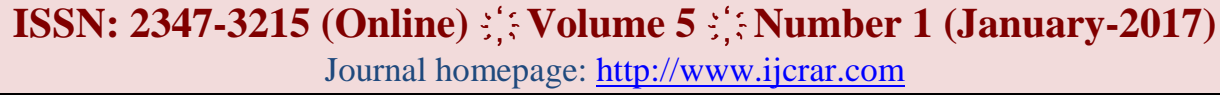 & \\
\hline
\end{tabular}

doi: http://dx.doi.org/10.20546/ijcrar.2017.501.008

\title{
Some Biological Parameters of Lucilia sericata M., (Diptera: Calliphoridae) Necrophagous Insect Breeding on Pig (Sus scrofa domesticus L.) and Beef's (Bos indicus) Liver at the National Center of Floristic, Guinean Zone of Ivoiry Coast
}

\author{
Y.C. Eurudice. Yapo ${ }^{1 *}$, L.R. Nondenot Aboua ${ }^{1}$, A. Franklin Koffi ${ }^{2}$ and Hassane Dao ${ }^{1}$ \\ ${ }^{1}$ Félix Houphouët Boigny University of Cocody-Abidjan, Ivory Coast, UFR Biosciences, Laboratory of Zoology and \\ Animal Biology, PO BOX 582 Abidjan 2222 \\ ${ }^{2}$ National Institute of Public Hygiene, Abidjan-Ivory Coast PO BOX V 14 Abidjan \\ *Corresponding author: daobonheur@gmail.com
}

\section{Abstract}

Insects pledged to the corpses are increasingly used for the postmortem interval determining. The aim of this work is to study the biological parameters of Lucilia sericata colonizing the liver of mammals in the Guinean zone of Ivory Coast for use in forensic. The study of the biological parameters revealed that L. sericata is an holometabol insect with three larval stages in the developmental cycle and a pupal stage. A female of $L$. sericata has laid on average of $1438.86 \pm 47.8$ eggs on pig liver, while that on beef liver it laid on average $1296.8 \pm 62.45$ eggs. The duration of the developmental cycle of $L$. sericataon the $B$. indicus liver of and $S$. scrofa domesticus was respectively $13.94 \pm 0.24$ days and $13.21 \pm 0.22$ days at a temperature of $26.85 \pm$ $0.90^{\circ} \mathrm{C}$ and a relative humidity of $88.7 \pm 1.3 \%$. In the semi-environmental condition, the emergence rate was higher on the pig's liver. The length of the development cycle was short on the pig's liver and long on that of beef. The sex-ratio was respectivily $0.86 \pm 0.05$ and $0.76 \pm 0.02$ on the of pig's liver and beef's liver. The male flies lived less longer than females.
\end{abstract}

\section{Article Info}

Accepted: 05 January 2017

Available Online: 20 January 2017

\section{Keywords}

Lucilia sericata, pig liver, beef liver, temperature development cycle.

\section{Introduction}

In more countries, such as the majority of African countries, criminal justice systems lack the means of investigation (UN, 2005). These lack of resources and appropriate methods, prevent the investigations to be carried out to the end. But forensic science can't always solve crime by its traditional methods, hence the use of forensic entomology (Gennard, 2007). This science although it is a component of forensic science, is interested in the use of necrophagous insects. In contrast to the medical examiner, to estimate the time and cause of death stricto sensu, the entomologist forensics evaluates when was the beginning of the colonization of the corpse by insects (Charabidze, 2008). The insects colonizing the corpses are precious pieces of investigations, for the investigators. Different species occur over time on the corpses, depending it stage of decomposition (Benecke, 2004). Insects use the body decomposing for oviposition and survival of their larvae. It is in this context that scientific police increasingly use this science as criminal investigative tools. Several 
insects of forensic importance were studies in temperate countries (Marchenko, 1988; Wyss and Cherix, 2006; Charabidze, 2008). In Ivory Coast, the literature mentions no studies on the biology of insects for forensic use. The general objective of this work is to study the biological parameters of Lucilia sericata colonizing the mammals' liver in the Guinean zone of Ivory Coast.

\section{Material and Methods}

\section{Study site}

The study was conducted at the national center of floristic (CNF), located at the Félix Houphouët Boigny University $\left(05^{\circ} 20^{\prime} \mathrm{N}-03^{\circ} 65^{\prime} \mathrm{W}\right)$. The rate of saturation of the soil is below $20 \%$. The organic content is quite low (2-3\%). In soil level, the horizon humifere is thin. The CNF is a fully planted forest environment that includes a botanical garden consisting partly of fallow and an arboretum (Kouakou, 2009). The temperature varied between 24.2 and $30^{\circ} \mathrm{C}$. Relative humidity fluctuated between 84.6 and $91.5 \%$. The follow-up was conducted from august 02, 2015 to 03 october 2015.

\section{Material}

The biological material was made up of Lucilia sericata, necrophagous fly breeding on the liver of mammals, (pig and beef). The strain of Lucilia sericata has been formed from individuals emerged on the liver of pig or beef exposed to the CNF. The measurement of the temperature and the relative humidity was made possible by a thermo-hygrometer (HMI 172SI) detachable recorder. To make swab, flexible metal pliers and some pill boxes were used. The observations and egg counts were made at the binocular magnifying grlassbrand Optika. Identification guides flies have been used for the identification of flies (Scholtz and Holm, 1996; Bobby, 2006; Szpila, 2014, Irish1, 2014). The breeding have been made in plexiglas cages containing the sand sterilised in an autoclave at a temperature of $121^{\circ} \mathrm{C}$ and at a pressure of $1.5 \mathrm{bar}$.

\section{Methods}

\section{Breeding conditions}

Breeding were conducted at the National Center of floristics in ambient conditions, at a temperature ranging from $24.20 \pm 0,9^{\circ} \mathrm{C}$ to $30 \pm 1.1^{\circ} \mathrm{C}$ and a relative humidity between 84.6 and $91.5 \%$. Average values were respectively $26.85 \pm 0.9^{\circ} \mathrm{C}$ and $88.7 \pm 1.3 \%$. The values of temperature and relative humidity were identified every day, the morning at $6 \mathrm{AM}$, at noon and at $6 \mathrm{PM}$. These data have been reduced to the daily average.

\section{Flies mass breeding}

A kilogram of pig or beef's liver was arranged each in a bin of plastic in the open air. After 12 hours of exposure, the bins containing substrates infested flies' eggs, have been removed, then the substrates were placed in cages of breeding. The follow-up was done until the emergence of new flies. After emergence, obtained flies have been identified in order to obtain the species Lucilia sericata for the realization of specific breeding.

\section{Specific breeding of Lucilia sericata}

Ten couples of flies have been introduced in breeding cages. To release the vitellogenesis in females, $50 \mathrm{ml}$ of blood of pig or beef (protein source) has been available to them (Alonso et al., 2015). Twelve hours later the blood was removed and then pieces of pig's liver or beef's liver weighing $200 \mathrm{~g}$ were placed in each breeding cage. The time of the first eggsspawning were noted. The insects were removed 8 hours later. The eggs have been followed until the emergence of the adult. These flies have been used to carry out the different experiments.

\section{Determination of biological parameters}

\section{Number of eggs laid by the female and duration of eggs incubation}

For the experiments, 30 couples of Lucilia sericata have been considered. To determine the number of eggs laid (Oi) and the duration of the incubation period for eggs, 6 pairs of fly were considered among the 30 used for the tests. Thus, eggs deposited on the pig or beef's liver was counted for each of 6 females, under binocular magnifying glass. The average number of eggs laid by the female $(F)$ was calculated.

$\mathrm{F}=\frac{\sum O \mathrm{iri}}{\sum r i}$

Oi: number of eggs; ri: number of females

Infested beef or pig's liver has been incubating in a breeding cage sand slightly moistened and sterilized container. The eggs have been observed, every day, until hatching. The average incubation period $(\mathrm{Pi})$, which is 
understood time between $(\mathrm{P})$ spawning and hatching eggs (E) were noted.

$\mathbf{P i}=\frac{\sum \text { tivi }}{\sum v i}$

$\mathrm{ti}=\mathrm{E}-\mathrm{P}$

vi: number of hatched eggs

\section{Determining the duration of the development cycle}

To determine the duration of larval development, pupation and duration of pupal development, experiments were carried out using 10 larvae from the eggs laid by each of the 30 females. Thus, after hatching, daily monitoring of stage 1 larvae was carried out on decomposing pig or beef liver. The different stages of larval development were determined by respiratory stigma. The duration of larval development is the time between the eggs laying and the stage 3 larvae. This period is the sum of the passage time from L1 to L2 and that of L2 to L3 (t1) noted (DL).

$$
\mathrm{DL}=\frac{\sum \mathrm{diki}}{\sum \mathrm{ki}}
$$

$\mathrm{di}=\mathrm{t} 1 ; \mathrm{ki}$ : number of stage 1 larvae

The time between the larvae of stage 3 (JL) and that of the pupa (Jp) is the post-feeding phase noted (P).

$\mathbf{P}=\frac{\sum \text { fisi }}{\sum s i}$

fi = Jp-JL; If: larval size L3

The duration of the pupa which is the time separating the pupation $(\mathrm{P})$ from the emergence of the adult (Ea) denoted Dp.

$$
\mathbf{D p}=\frac{\sum_{\text {gizi }}}{\sum \mathbf{z i}}
$$

gi = Ea-P; zi: number of pups

Total development time is the period between egg laying and adult DC.

$\mathrm{DC}=\mathrm{Pi}+\mathrm{DL}+\mathrm{P}+\mathrm{Dp}$

DC: Duration of development cycle; Pi: Incubation period of eggs; DL: Larval duration; P: Duration of the post-feeding phase; Dp: Pupal duration
Determination of the effect of temperature on the development time

The study of the effect of temperature on the duration of development of the life cycle of $L$. sericata was determined. For this purpose, 30 larvae were each introduced into a breeding cage at intervals of five days. The experiment was repeated three times. At the exposure of the substrates to the eggs, the temperature was taken every morning at 6 o'clock am, at noon and evening at 6 o'clock pm. These three temperatures are brought back to a daily average temperature. The observations were made until the emergence of the imagos. When emergence occurs in a cage, temperatures taken from the beginning are brought back to the mean temperature of the cycle.

\section{Determination of emergence and sexual rates}

The mean rate of emergence ( $\mathrm{Te}$ ) is the ratio expressed in percentage, from the number of adults emerged to the number of eggs laid by a female.

$T e=\frac{N e}{N \text { to }} \times 100$

Te: Percentage emergence rate; Ne: Number of adults emerged; Nto: Total number of eggs laid.

The sex-ratio is the ratio of the number of males emerged to the number females emerged. Emerging rates and sex ratio were calculated for the offspring of each female.

Sex-ratio $=\frac{\text { Number ofmales }}{\text { Number of females }}$

\section{Lifetime of flies}

The thirty pairs of flies were each placed in a breeding box containing $100 \mathrm{~g}$ of pig or beef liver and sugar water. Every 24 hours, the substrates were removed and replaced by another until insects died. The number of dead imagos was raised every day, until the death of the last individual. The average duration of life (Dv) of imagos, expressed in days, has been determined from the results achieved by establishing the difference of the sum of the products of the different lengths of life (xi) by the number of insects dead (ni) to the sum of the total of dead insects.

$D v==\frac{\sum x i n i}{\sum n i}$

xi: lifetime; ni: number of insects 


\section{Statistical analysis}

The processing of the data was carried out using the software Statistica version 7.1. An analysis of two-factor variance (ANOVA) followed by the Newman-Keuls test at the 5\% threshold allowed us to assess the homogeneity of the samples. Correlations between temperatures and durations of the development cycle were established using the Pearson test.

\section{Results and Discussion}

\section{Number of eggs laid and incubation duration}

In our experimental conditions, females of Lucilia sericata have laid, during their lives, a maximum of 1867 and a minimum of 885 eggs, whether an average of $1438,86 \pm 47,88$ eggs on pig's liver, while they have laid a minimum of 765 and a maximum of 1785 eggs with an average of $1140,53 \pm 65,86$ eggs on beef's liver. The ANOVA test followed by the test of separation of Newman-Keuls on the threshold of $5 \%(\mathrm{~F}=13,423$; ddl $=1 ; \mathrm{P}=0,000054)$ indicated a significant difference between the values obtained (Figure 1). The period of incubation of the eggs of 1 . sericata has varied from 0.5 to 0.7 day, or an average of $0.53 \pm 0.01$ day on the liver of pig while it was between 0.47 and 0.7 day with an average of $0.62 \pm 0.01$ on the beef liver. The ANOVA test followed by the test of separation of Newman-Keuls on the threshold of $5 \%(\mathrm{~F}=39,68 ; \mathrm{ddl}=1 ;) \mathrm{P}=0.00000)$ indicated a significant difference between the values obtained (table 1 ).

\section{Average the development cycle time}

The development cycle of Lucilia sericata went through three larval stages and a pupal stage. In this species, the passage of the first stage to the post-feeding stage took 5 to 7 days, whether an average of $5.26 \pm 0.11$ days on the pig's liver, while on the beef liver, larval development is carried out for 5 to 8 days, whether an average of $5.73 \pm$ 0.17 days. The ANOVA test followed by the test of separation of Newman-Keuls on the threshold of $5 \%(\mathrm{~F}=$ 5.62; $\mathrm{ddl}=1 ; \mathrm{P}=0.0200)$ indicated a significant difference between the values obtained. The duration of larval development was shorter on the pig's liver thanin the beef's liver. The post-feeding phase, the time between the formation of the pupa from the third-stage larva was 1 to 3 days with an average of $1.36 \pm 0.08$ on the pig's liver while on the beef's liver, this period was $1.56 \pm 0.09$ days. The ANOVA test followed by the test of separation of Newman-Keuls on the threshold of $5 \%$
$(\mathrm{F}=2.4279 ; \mathrm{ddl}=1 ; \mathrm{P}=0.1246)$ indicated no significant difference between the values obtained (table 1 ).

Development of the pupa into an adult individual is made for 5-7 days on the pig's liver with a average duration of $5.7 \pm 0.13$ days while it was 5 to 8 days with an average of $6.03 \pm 0.16$ days on beef's liver. The ANOVA test followed by the test of separation of Newman-Keuls on the threshold of $5 \%(\mathrm{~F}=2.741 ; \mathrm{ddl}=1 ;) \mathrm{P}=0.10320)$ indicated no significant difference between the values obtained (table 1). The total duration of development of Lucilia sericata has been $13.21 \pm 0.22$ days on the pig's liver (S. scrofa domesticus) while it was $13.94 \pm 0.24$ days on beef's liver (B. indicus) (Fig 2). The ANOVA test followed by the test of separation of Newman Keuls on the threshold of $5 \%(\mathrm{~F}=5.015 ; \mathrm{ddl}=1 ; \mathrm{P}=0.0289)$ indicated a significant difference between the values obtained (table 1). Linear regression between the duration of the cycle development and the ambient temperature of the study site has shown that this linking time decreases when the temperature rises on the pig liver $(\mathrm{r} 2=0,939 ; \mathrm{P}<0.01)$ (Fig 3$)$ and on beef liver ( $\mathrm{r} 2=$ 0.925 ; $\mathrm{P}<0.01$ ) (Fig 4).

\section{Emergence rate of and sex-ratio}

The emergence average rate of Lucilia sericata on pig ( $S$. scrofa domesticus) liver and beef liver were respectively $73.07 \pm 2.48$ and $60.47 \pm 1.74$. The ANOVA test followed by the test of separation of Newman-Keuls on the threshold of $5 \%(\mathrm{~F}=17.29 ; \mathrm{ddl}=1 ; \mathrm{P}=0.0000)$ indicated a significant difference between the values obtained (table 2). The sex-ratio of Lucilia sericata on pig's liver was $0.86 \pm 0.05$ and on beef's liver $(B$. indicus) was $0.76 \pm 0.02$ (table 2).

\section{Lifetime of the adult flies}

The average lives of the males and females of Lucilia sericata have been respectively $27.26 \pm 0.76$ and $34.86 \pm$ 0.67 days on the liver of pig. The ANOVA test followed by the test of separation of Newman-Keuls on the threshold of $5 \%(\mathrm{~F}=55.876 ; \mathrm{ddl}=1 ; \mathrm{P}=0.0000)$ indicated a significant difference between the values obtained. They were respectively $24.83 \pm 0.30$ and 29.33 \pm 0.58 day on beef liver (Fig 5). The ANOVA test followed by the test of separation of Newman-Keuls on the threshold of $5 \%(\mathrm{~F}=46.751 ; \mathrm{ddl}=1 ; \mathrm{P}=0.0000)$ indicated a significant difference between the values obtained. The ANOVA test followed by the NewmanKeuls test to the 5\% threshold, $(\mathrm{F}=49.877 ; \mathrm{ddl}=3 ; \mathrm{P}=$ $0.000)$ revealed significant differences between the 
average lifespans of males and females of Lucilia sericata on two substrates of breeding. The average lifetime of this species has been longer on pig (31.06 \pm 0.71 days) on the beef ( $27.08 \pm 014$ days).

The average number of eggs laid by a female of $L$. sericata during his life was higher on the liver of pig ( $S$. scrofa domesticus) than on beef liver (B.indicus). This difference could be due to a preference of laying support by the insect. The female explores the substrate using her ovipositor (Abou, 2004), in order to ensure the right conditions of incubation of their eggs before oviposition (Cortesero, 1994). Pig's liver would be richer in protein than beef. This argument is similar to that of Barton Brown et al. (1976) and Charabidze (2008) which reported that the females were able to detect a meal rich in protein, necessary for the onset of vitellogenesis, a precursor to the formation of eggs. Significant differences were found for the average duration of each stage of the development cycle (larval development, pupation and pupal development) on $S$. scrofa domesticus liver and beef liver. The development cycle of $L$. sericata has been longer on beef's liver than on the pig'sliver. This would be due to the chemical composition and the speed of putrefaction of the substrate. Indeed studies of different type of meat per Day and Wallman, (2006) showed that all tissues don't have the same nutritional value for the Diptera larvae. The development duration of larvae of Calliphoravicina breeding on beef's liver and pig were different (Clark et al., 2006). The comparison of substrate of different animal said faster development on the liver of pigthan beef (Clark et al., 2006). The study of the effect of temperature on the length of the development cycle when the temperature increases, the length of the development cycle decreases and it work on both types of substrate. The temperature increase would be for the increase of the metabolic reactions of larvae of $\mathrm{L}$. sericata. These reactions would be originally from the increase in the speed of development of flies. These comments match those of Charabidze, (2008) which in its work noted that the aggregation of dipteran larvae produced increased local temperature, which would be at the origin of the rapid growth of the larvae. The emergence rate was higher on the pig's liver than on beef's liver. This difference is due to the fact that the pig's liver is more propiste to the development of $L$. sericata, in light of its richness in nutrients, especially ammonia Hobson (1932).

Table 1. Development time of Lucilia sericata on beef and pig's liver

\begin{tabular}{|l|l|l|l|l|l|l|}
\hline Substrates & \multicolumn{1}{|c|}{$\begin{array}{c}\text { Number of } \\
\text { laid eggs }\end{array}$} & $\begin{array}{c}\text { Incubation } \\
\text { Duration rate }\end{array}$ & \multicolumn{1}{|c|}{$\begin{array}{c}\text { Larval } \\
\text { duration }\end{array}$} & $\begin{array}{c}\text { Post-feeding } \\
\text { time }\end{array}$ & Pupal duration & $\begin{array}{c}\text { Total } \\
\text { developmental } \\
\text { cycle duration }\end{array}$ \\
\hline Beef's liver & $1296.8 \pm 62,45^{\mathrm{b}}$ & $0.62 \pm 0,01^{\mathrm{a}}$ & $5.73 \pm 0.17^{\mathrm{a}}$ & $1.56 \pm 0.09^{\mathrm{a}}$ & $6.03 \pm 0.16^{\mathrm{a}}$ & $13.94 \pm 0.24^{\mathrm{a}}$ \\
\hline Pig's liver & $1438.86 \pm 47,8^{\mathrm{a}}$ & $0.53 \pm 0,01^{\mathrm{b}}$ & $5.26 \pm 0.11^{\mathrm{b}}$ & $1.36 \pm 0.08^{\mathrm{b}}$ & $5.7 \pm 0.13^{\mathrm{b}}$ & $13.21 \pm 0.22^{\mathrm{b}}$ \\
\hline$P$-value & 0.08 & 0.00001 & 0.0200 & 0.1246 & 0.1032 & 0.0289 \\
\hline$d d l$ & 1 & 1 & 1 & 1 & 1 & 1 \\
\hline$F$ & 3.26 & 39.685 & 5.62 & 2.4279 & 2.741 & 5.015 \\
\hline
\end{tabular}

ANOVA followed by the Newman Keuls test at the $5 \%$ threshold; $\mathrm{N}=30$;

NB: Figures followed by the same letters in the same column are not significantly different at the $5 \%$ threshold according to the Newman Keuls test

Table 2. Emergence rate et Sex-ratio rate

\begin{tabular}{|l|l|l|}
\hline Breeding substrate & Emergence rate $(\%)$ & Sex-ratio $(\%)$ \\
\hline Beef's liver & $60.47 \pm 1.74^{\mathrm{b}}$ & $0.76 \pm 0.02^{\mathrm{b}}$ \\
\hline Pig's liver & $73.07 \pm 2.48^{\mathrm{a}}$ & $0.86 \pm 0.05^{\mathrm{a}}$ \\
\hline$P$-value & 0,000 & 0.05 \\
\hline$d d l$ & 1 & 1 \\
\hline$F$ & $\mathrm{~F}=17.29$ & 3.85 \\
\hline
\end{tabular}

ANOVA followed by the Newman Keuls test at the $5 \%$ threshold; $\mathrm{N}=30$;

NB: Figures followed by the same letters in the same column are not significantly different at the $5 \%$ threshold according to the Newman Keuls test 
Fig 1. Quantity of eggs laid by a female on each substrate

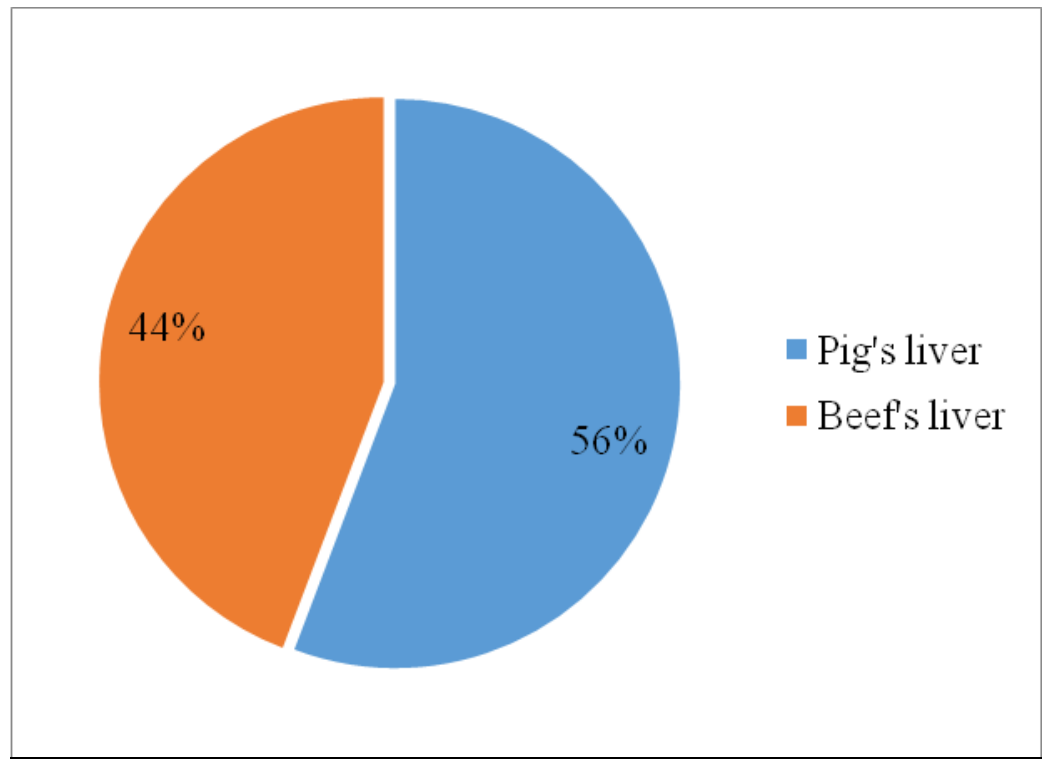

Fig 2. Lucilia sericata development cycle
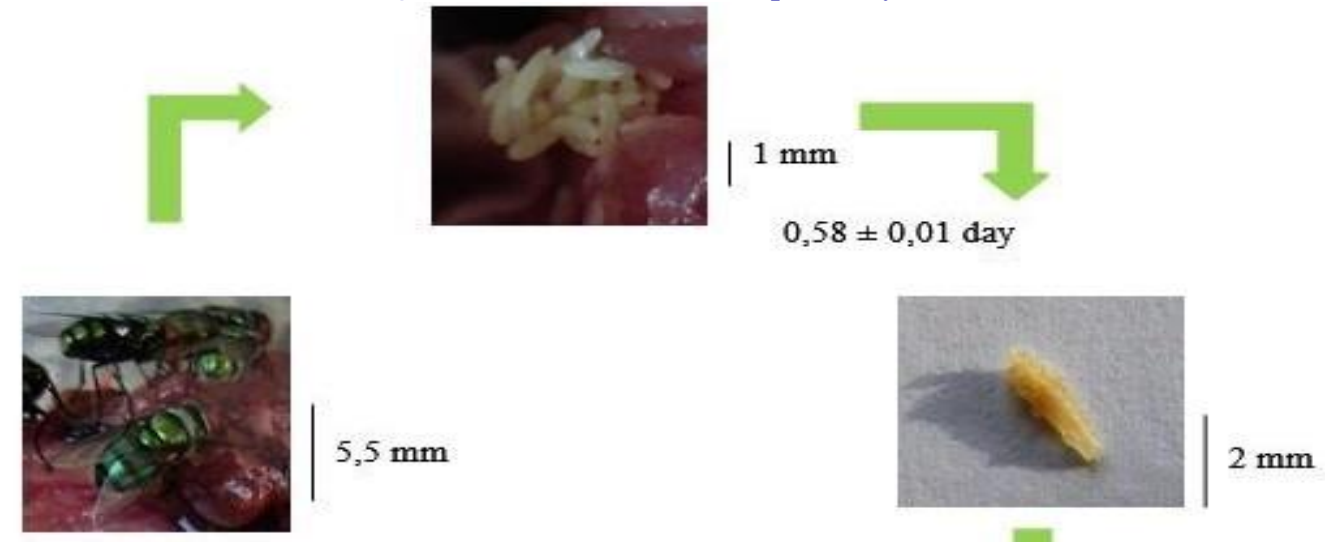

$5,86 \pm 0,13$ days

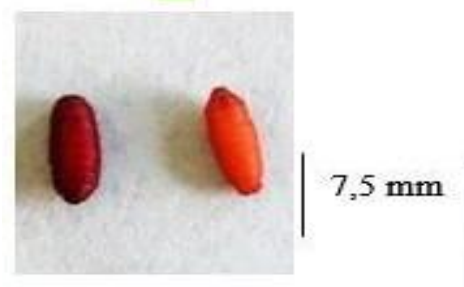

$$
7,06 \pm 0,14 \text { days }
$$
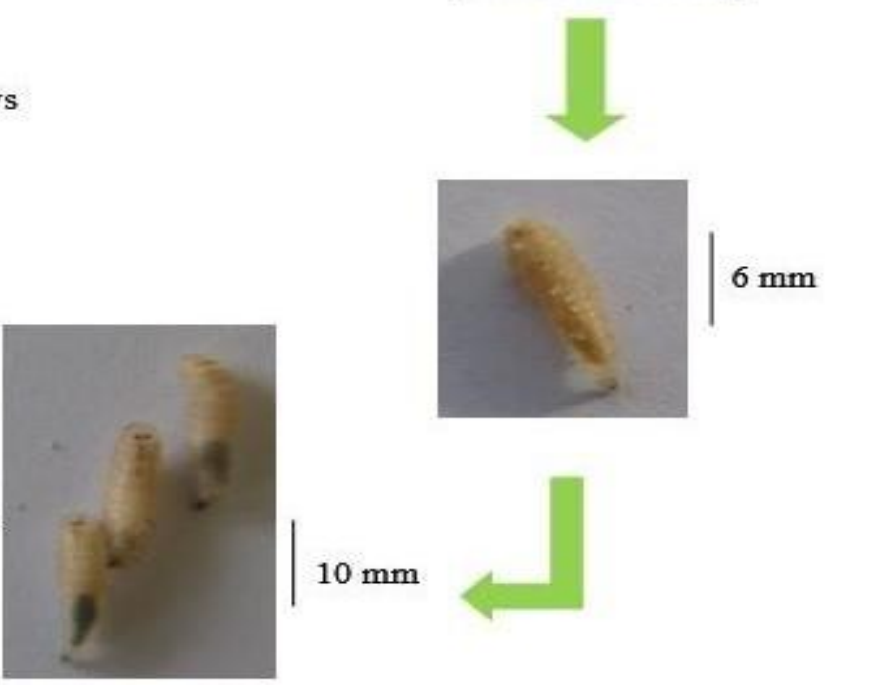
Fig 3. Relationship between temperature and the cycle duration on beef's liver

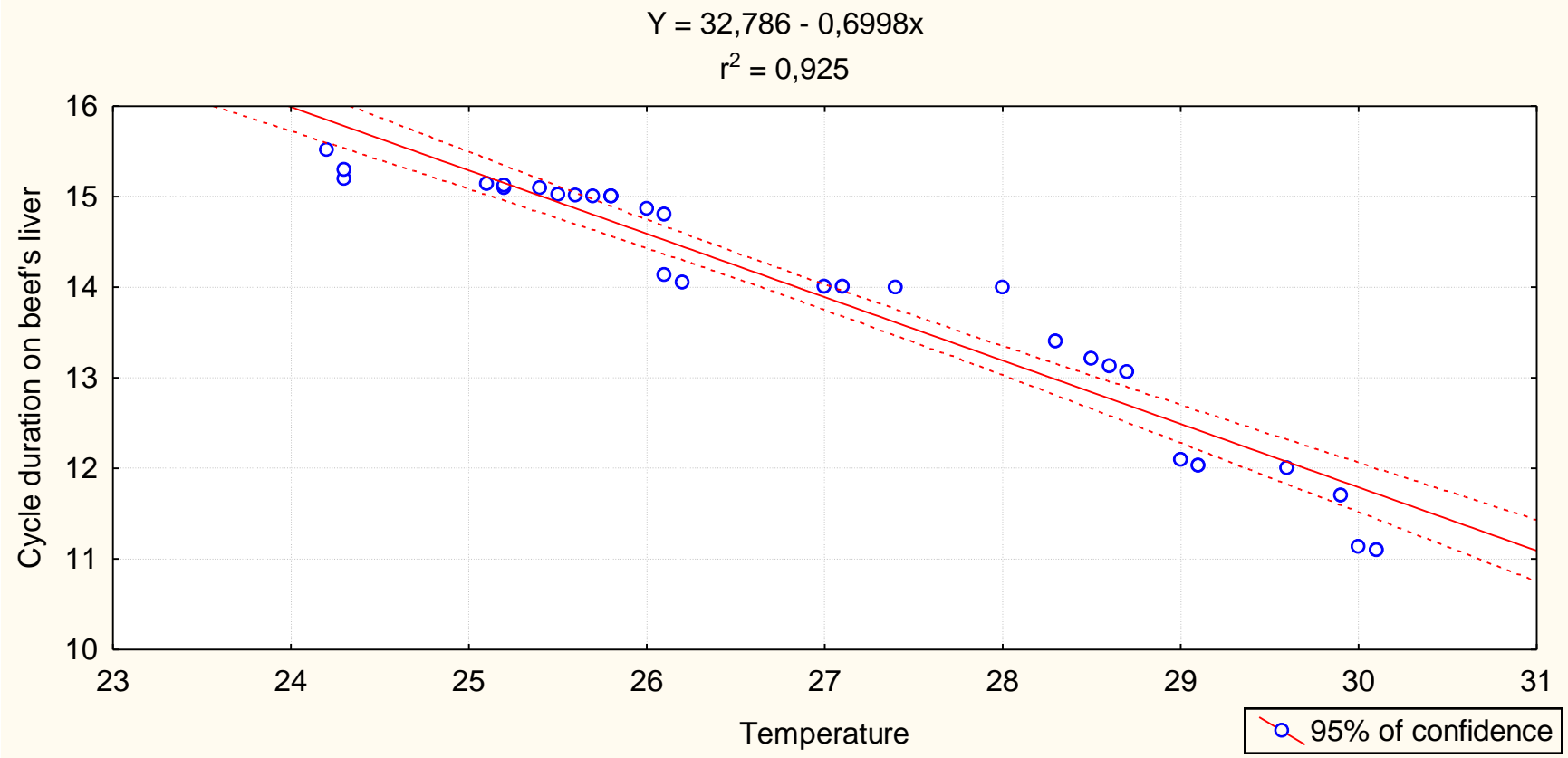

Fig 4. Relationship between temperature and the cycle duration on pig's liver




Fig 5. Longevity of adults of Lucilia sericata; ANOVA followed by the Newman Keuls test to the 5\% threshold; Beef's liver (M1 - F1): $\mathrm{F}=55.876 . \mathrm{ddl}=3 ; \mathrm{P}=0.0000 ;$ Pig's liver $(\mathrm{M} 2-\mathrm{F} 2): \mathrm{F}=46.751 ; \mathrm{ddl}=3 ; \mathrm{P}=0.0000$

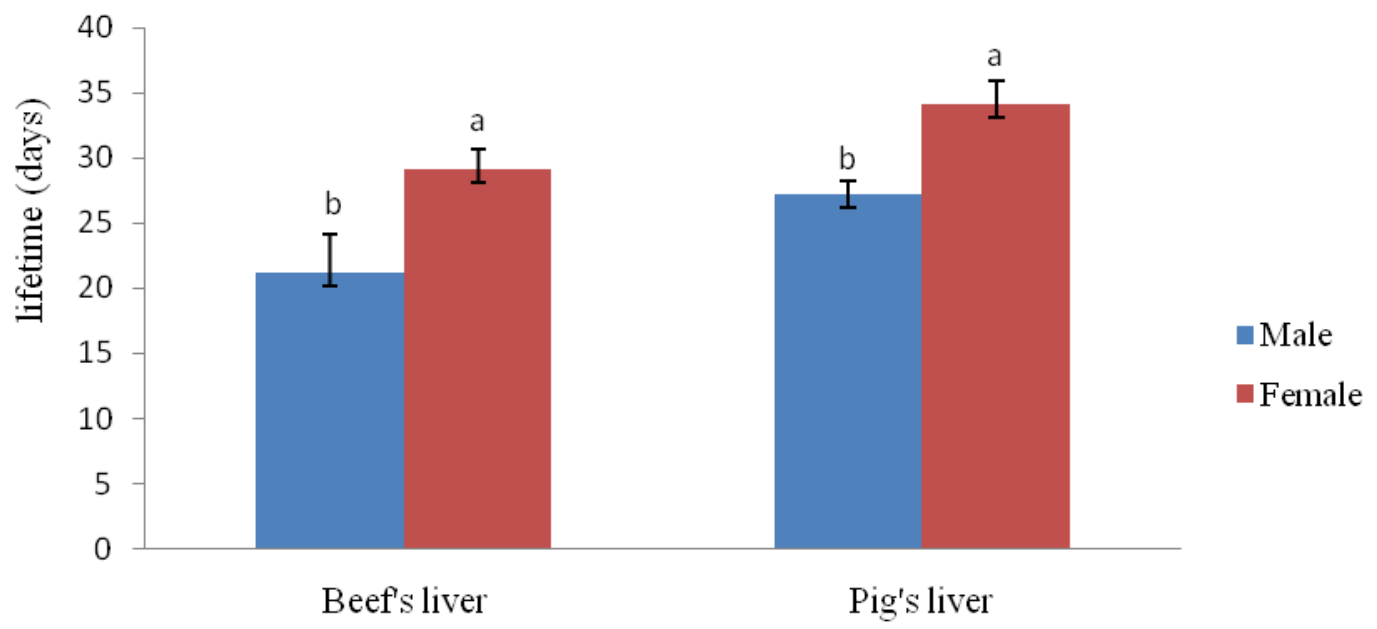

Breeding substrate

According to this author, the alkalization of the substrate of breeding by the manufactured substances would facilitate the digestion of substances ingested by the larvae of $L$. sericata. There is no significant difference between the sex-ratios observed at the level of the two substrates. The sex-ratios $(0.76 \pm 0.02$ on beef liver $)$ and $0.86 \pm 0.05$ on the pig liver obtained were for females. The fact that the sex-ratio has been in favour of females appears to increase the reproductive potential of the species (Tano et al., 2010). The analyses carried out revealed that emerged females were more numerous than males within the breeding two substrates. Males of Lucilia sericata lives were shorter than those of females, both on the liver of pig (S. scrofa domesticus) on beef liver (B. indicus). Similar results were observed by Tarone et al. (2011) on the corpses of beef and pig. The short life expectancy of males could be attributed to the energy released during the mating. This argument has also been issued by Rueda et al. (2010) studying table of life on two circles of artificial breeding of Diptarian species. The reproduction activity contributes to a significant reduction of the lifetime of males and females. That's what Williams (1984) described as 'cost of reproduction', concept that links the reproductive effort to the other functions of the insect.

\section{Conclusion}

The study of the biological parameters revealed that $L$. sericata is a holometabol insect with three larval stages in the development cycle and a pupal stage. The duration of the cycle of development on the liver B. indicus and $S$. scrofa domesticus was respectively $13.94 \pm 0.24$ days and $13.21 \pm 0.22$ days at a temperature of $26.85 \pm 0.90^{\circ} \mathrm{C}$ and a relative humidity of $88.7 \pm 1.3 \%$. The male flies lived longer than females. A female of $L$. sericata has laid on average $1438.86 \pm 47.8$ eggs on pork liver, while that on beef liver she laid on average 1296,8 \pm 62.45 eggs. In land condition, the rate of emergence was higher on the pork liver. The sex-ratio was $0.86 \pm 0.05$ and 0.76 \pm 0.02 on the pig and beef's liver. The length of the development cycle was short on the pig's liver and long on that of beef. The study of the biological parameters of L. sericata and those of other necrophagous insects in different climate zones of Côte d'Ivoire would elucidate many murders in the perspective of social justice.

\section{Acknowledgments}

These work under the project PASRES $\mathrm{N}^{\mathrm{o}} 130$. We would like to thank the Executive of this structure that continues to provide assistance to researchers. We thank the Director of the National Center of floristics of allowing us to perform our work within the Botanical Garden. We also thank the Director of the Institute of Public Hygiene (INHP)health, who has given us a laboratory without any time forget all those who have helped for the correction and improvement of this article.

\section{References}

Aboua, L.R.N. 2004. Activité parasitaire et comportement trophique de Dinarmus basalis Rondani (Hymenoptera: Pteromalididae et de Eupelmus vuilleti Crawford) en présence de leur hôte Callosobruchus maculatus FAB. (Coleoptera 
Bruchidae) ravageur des stocks de Niébé. Thèse de Doctorat, Université de Cocody, 179p.

Barton Brown, L., Bartell, R. J., Van Gerwen, A.C.M., and Lawrence, L.A. 1976. Relationship between protein in gestion and sexual receptivity in females of the Australian sheep blowfly Lucilia cuprina. Physiol. Entomol., 1.

Charabidze, D., et Bourel, B. 2008. Entomologie médico-légale, les insectes au servicede la justice. Revue Insecte, 147: 104-109.

Clark, K., Evans, L., Wall, R. 2006. Growth rates of the blowfly, Lucilia sericata, on different body tissues Forensic Sci. Int., 156: 145-149.

Cortesero, A.M. 1994. La recherche de l'hôte chez Eupelus vuilleti (Crawford). Analyse des Relations tritrophiques entre la plante (Vigna unguiculata Walp), l'hôte (Bruchdius atrolineatus Pic) et le parasitoïde. Thèse de Doctorat, Université de Tours, $134 \mathrm{p}$.

Day, D.M., et Wallman, J.F. 2006. Width as an alternative measurement to length for post-mortem. Entomologie judiciaire: utilisation des insectes dans les enquêtes sur les décès, Forensic Sci. Int., 159: 158-167.

Hobson, R.P. 1932. Studies on the nutritionofblowfly larvae: IV. The normal role of micro-organism in larval growth. J. Experience Biol., 9: 366- 77.

Irish, S., Lindsay, T. and Wyatt, N. 2014. Key to adults of Afrotropical species of the genus Chrysomya Robineau-Desvoidy (Diptera: Calliphoridae). African Entomol., Vol. 22, No.2, 10p
Kouakou, Y.J.C. 2009. Etude de la biologie reproductive de Thitonia diversifolia (Hensl) GRAY (Asteraceae). Mémoire de Diplôme d'Etude Approfondi, Université de Cocody, 45p.

Marchenko, M.I. 1988. Medico-legal relevance of cadaver entomofauna for the determination of the time since death. Acta of the Medical and Legal Society, 38: 257-302.

Rueda, L.C., Ortega, L.G., Segura, N.A., Acero, V.M. and Bello, F. 2010. L. sericata train from Colomba: experimental Colonisation, life table and evaluation of two artificial diets of the blowfly Lucilia sericata (Meigen) (Diptera: Calliphoridae). Biol. Res., 43: 197-203.

Scholtz, C.H., et Holm, E. 1996. Insects of Southern Africa, $502 \mathrm{p}$.

Szpila, K. 2014. Key for identification of European and Mediteranean blowflies (Diptera, Calliphoridae) of forensic importance Adult flies. Nicolaus Copernic University Institute of Ecology and Environnental Protection Departement of Animal Ecoogy: 18p.

Tarone, A.M., et Foran, D.R. 2011. De l'expression des gènes au cours du développement dela mouche du coup : l'amélioration de la précision des estimations d'âge en entomologie médico-légale. J. Forensic 56: 112-122.

Williams, H.L. 1984. A model for the aging of fly larvae in forensic entomology. Forensic Int., 25: 1-9.

Wyss, C., et Cherix, D. 2006. Traité d'entomologie forensique. Presses Polytechniques et Universitaires Romandes, Lausanne, 317p.

\section{How to cite this article:}

Eurudice. Yapo, Y.C., L.R. Nondenot Aboua, A. Franklin Koffi and Hassane Dao. 2017. Some Biological Parameters of Lucilia sericata M., (Diptera: Calliphoridae) Necrophagous Insect Breeding on Pig (Sus scrofa domesticus L.) and Beef's (Bos indicus) Liver at the National Center of Floristic, Guinean Zone of Ivoiry Coast. Int.J.Curr.Res.Aca.Rev. 5(1), 68-76. doi: http://dx.doi.org/10.20546/ijcrar.2017.501.008 